\section{SUSTAINING A GLOBAL \\ COMMUNITY: ART AND \\ RELIGION IN THE NETWORK \\ OF BAROQUE HISPANIC- AMerican Paintings}

Juan Luis Suárez ${ }^{\dagger}$,

E-mail: <jsuarez@uwo.ca>

Fernando Sancho ${ }^{\dagger \neq}$,

E-mail: <fsancho@us.es>

Javier de la Rosa ${ }^{\dagger}$

E-mail: <versae@gmail.com>

$\dagger$ The CulturePlex Lab, University of Western-Ontario, London, ON, N6A 3K7, Canada.

Department of Computer Sciences and Artificial Intelligence, University of

Seville, Seville, Spain.

\section{Abstract}

The authors analyze the network of Hispanic baroque paintings from 1550 to 1850 . They divide the dataset of 11,443 works from Spain and Latin America into 25-year periods in order to study the evolution of the paintings' 211 descriptors. The analysis shows that most of the paintings are linked through genre and theme and that religious Christian themes make up the overwhelming majority of connections among the paintings.

\section{Introduction}

Heinrich et al. [1] have proven that the existence of norms that sustain fairness in exchanges among strangers are connected with the diffusion of insti-tutions such as market integration and the participation in world religions. Their research confirms the hypothesis that modern world religion may have contributed to the sustainability of large-scale societies and large-scale inter- actions; we propose that art is another institution that contributes to the rise and sustainability of large-scale societies. We use the case of the formation of an artistic network of paintings, schools, themes, genres, and artists whose development goes along with the expansion and colonization by the Hispanic Monarchy across America to show that this artistic network has a presence in all political territories, encompassing most ethnicities and religions of indigenous origin.

\section{Methodology}

The data set comprising the paintings from the Baroque period are organized and stored in a PostgreSQL web-based database [2]. It is important that the data includes more than 100,000 total topics (11,443 of them are artworks). A distinctive feature of the information is that it is organized around both text fields and adhoc descriptors that follow the model of a formal ontology [3].

For our study we have decided to model the data in one of the possible networks, a network created from common descriptors as weighted edges and artworks as nodes. Some pruning methods had to be applied in order to overcome some of the shortcomings resulting from the millions of edges and the excess of relational joins. We also split the dataset into 12 sections, each covering a 25 -year-period, from 1550 to 1850 [4].

\section{Research Questions}

Our research addresses the issue of the sustainability of communities through

Fig. 1. Baroque Paintings in the Hispanic World: A Network. The graph shows, for the first two periods of the study, the growth of the saints-related paintings as compared to the decrease of the cluster with virgins. Portraits' size remains more or less the same, but they get more connected to saints. (@ Javier de la Rosa.)
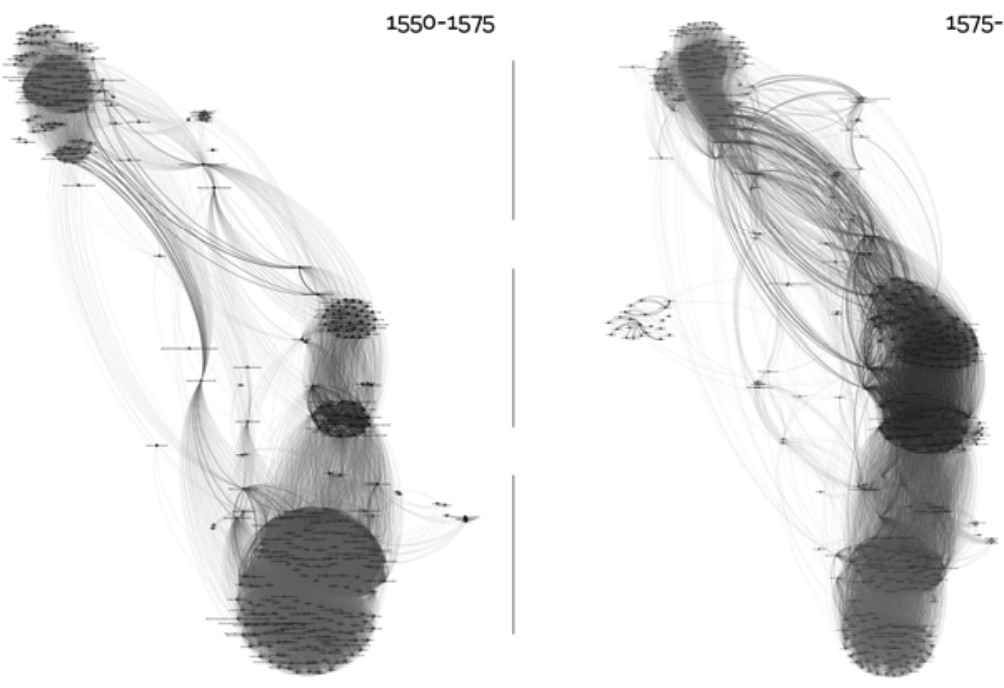

the existence of a flow of shared information. This question is of the utmost importance to understand the formation and dynamics of cultural groups and cultural areas. As important as the latter is the study of the spatial and temporal dimensions of any given political and cultural community, as this will shed light on the cultural processes resulting from previous and currents waves of globalization.

\section{Conclusions}

This research shows that art is a good candidate to articulate practices such as religious rituals that transmit and spread cultural information among a population, resulting in the formation of cultural communities as groups that share certain symbolic information that affects the behavior of individuals and groups. This information has been gathered in our database as the descriptors "civil", "religious", "portraits", "virgins" and "saints", and they follow different evolutions throughout the 12 periods analyzed.

In our case, the network of religious information carried out via the Baroque paintings that circulated in and between Spain and Latin America from the $16^{\text {th }}$ to the $18^{\text {th }}$ centuries points to the existence of a global community that shares many semantic descriptors. This network of cultural information also contains the elements to foster the creation of smaller, separate communities over time.

It is important to note that this artistic network guarantees the participation of distant populations into a world religion and that the public use of religious paintings in rituals and ceremonies demonstrates the existence of mechanisms associated with art and religion that foster pro-sociality and help keep the groups together.

\section{References and Notes}

This paper was presented as a contributed talk at Arts, Humanities, and Complex Networks - 2nd Leonardo satellite symposium at NetSci2011. See $<\mathrm{http}: / /$ artshumanities.netsci2011.net $>$.

1. Joseph Heinrich et al. "Markets, Religion, Community Size, and the Evolution of Fairness and Punishment." Science 327, 5972, 2010.

2. BaroqueArt,

$<$ http://baroqueart.cultureplex.ca/>, accessed 1 September 2011.

3. CulturePlex Ontologies,

$<$ http://ontologies.cultureplex.ca/>, accessed 1 September 2011.

4. Baroque Paintings in the Hispanic World, $<$ http://zoom.it/A1wx\#full >, accessed 1 September 2011. 